\title{
Doing time and college: An examination of carceral influences on experiences in post- secondary correctional education
}

\author{
by LINDSEY LIVINGSTON RUNELL \\ Kutztown University
}

\begin{abstract}
Imprisonment pains often accompany confinement to correctional institutions. Less is known about how related discomforts and deprivations might specifically impact the administration and receipt of postsecondary correctional education. This paper will show how encounters between incarcerated college students, other prisoners, prison educators and corrections officers can influence higher learning in correctional settings. It is based on a qualitative study and inductive analysis of data collected from interviews with 34 formerly incarcerated individuals who were also past and present members of a higher education program in the United States post-release. This research has important policy implications given that incarcerated persons who engage in productive activities such as higher education are better positioned to cope with carceral strains in legitimate ways. It can also help educators and correctional staff develop programs that account for the specific educational challenges of the prison sub-culture.
\end{abstract}

Key words: Imprisonment pains, postsecondary correctional education, corrections officers, prison educators

\section{Introduction}

There is a proven link between receiving a postsecondary education in prison, ${ }^{1}$ reduced likelihood of recidivism, and successful reentry through gainful employment and social connections (Batuik et al., 2005; Chappell, 2004; Kim \& Clark, 2013). This evidence has contributed to the recent, modest growth of funding support for college programs in the United States correctional system (Anders et al., 2011; Meyer, 2013; Whiteside, 2015). ${ }^{2}$ Such advancements warrant the need for more attention paid to the experiences of the prisoners taking college classes. Of particular import are certain institutional features and relationships that frame the administration and receipt of postsecondary education in prison (Palmer, 2012; Winterfield et al., 2009).

Imposed restrictions on movement and interactions with others are an inherent part of incarceration. This reality is often stressful and contributes to various strains for incarcerated persons. Being involved in higher education can help individuals cope with imprisonment pains, yet such educational experiences are bounded in correctional settings. In carceral environments, interactions between prisoner college students, other incarcerated persons, faculty members and corrections officers are limited to structured contacts. This can create a culture of incarceration that affects classroom life in prison (Behan, 2007).

Encounters such as these affect the pursuit of postsecondary correctional education ("postsecondary CE") (Van Gundy et al., 2013). Evidence suggests that "prior accomplishments, verbal feedback provided by significant others and vicarious learning" influence self-efficacy or one's subjective beliefs about their potential to successfully complete academic tasks (Allred, et al. 2013, p. 213; Stevens et al., 2004). This self referential process is situational in nature and closely tied to environmental factors. If we adopt this standpoint and reflect on education in prison, it is important to remind ourselves that prisons are constructed such that they restrict the personal freedom and comforts of individuals confined to those spaces (Kaposy \& Bandrauk, 2012). For instance, studying in prison can prove challenging given the noise, chaos and violence which typically characterizes correctional facilities and detracts from educational activities (Kuhlman \& Ruddell, 2005). 
Carceral norms thus appear to contradict "the requisites of academic culture" and potentially interfere with opportunities for educational engagement in general (Allred et al., 2013, p. 215).

\section{Carceral Strains and Experiences in Postsecondary Correctional Education}

Pains of imprisonment arise in a number of ways, including through interactions with others in carceral contexts (Johnson, 2001; Sykes, 1958; Toch, et al., 1987). Agnew's general strain theory (GST) is useful for explaining this process. Under the GST, individuals are likely to experience strain when presented with negative stimuli, due to a failure to achieve, or loss of, positively valued stimuli. Indeed, people who develop a negative emotional state such as frustration or anger in response are more prone to engage in delinquent and criminal coping (Agnew, 2001, 2006). Some scholars suggest that the general strain theory is crucial to understanding how imprisonment pains derived from prisoner deprivations contribute to an increased risk of psychological harm, retreatism and subsequent reoffending (Blevins et al., 2010; Dye, 2010; Listwan, et al., 2010). As such, incarcerated persons might feel distressed over various elements of confinement like erratic supervision or blocked efforts to enjoy earned privileges such as involvement in higher education (Listwan, et al., 2013). Consequently, some incarcerated persons abandon legitimate goals and expectations as a coping mechanism, to avoid "chasing 'carrots' that might not be obtained" (Crewe, 2011, p. 458).

Less is known about the specific imprisonment pains experienced by incarcerated college students as they routinely interact with other prisoners, corrections officers and educational staff, and the strategies they use to reconcile these overlapping, yet distinct relationships. Moreover, do experiences in postsecondary $\mathrm{CE}$, however fragmented, help incarcerated college students manage pains of imprisonment and associated strains? This inquiry into the value of carceral participation in higher education is timely and important given that often times opportunities for completion are marred by restrictions on class availability, sentence length and administrative segregation placements (Palmer, 2012). Such challenges are due in part to imposed rules, some of which are discretionary, that govern the frequency and duration of individual movements in prison facilities.

Given these institutional norms, it is no surprise that relationships between corrections officers and prisoners are at the center of incarceration experiences (Crewe, 2011; Gordon et al., 2013; Listwan, 2013). Indeed, corrections officers play a pivotal role in shaping participation in postsecondary CE through their routine exercise of broad discretionary powers, which can result in a wide range of limitations on the use of educational facilities. As previously mentioned, the transformative power of completing a higher education in carceral settings is multifaceted and well documented. "In this respect, officers are crucial in mediating the forms of psychological power that are among the main sources of hope and frustration for prisoners, especially those on longer sentences" (Crewe, 2011, p. 469; see also Sykes, 1958).

Yet, a primary function of correctional security work is to maintain prison order by deterring threats to safety posed by incarcerated individuals. Accordingly, research shows that most assaults committed by incarcerated persons against correctional staff occur during routine movements as they enter and leave designated prison areas and are asked to display identification (Gordon et al., 2013). It is possible for these and other carceral conditions to influence officer decisions about whether to allow student travel to and from classrooms. Complicating this issue is the fact that officers are not obligated to disclose the reasons behind their regular use of authority, even if it constrains participation in postsecondary CE. As a result, correctional facilities are coercive institutions where deficits in information and personal autonomy are commonplace. It is under these conditions that "prison subculture develops as a response to the afflictions and limitations of confinement" (Sykes, 1958).

The components of any given culture of incarceration might vary across institutions. Yet, feelings of mistrust often coincide with carceral interactions and contribute to prison norms, expectations and values (Behan, 2007). These circumstances present complex challenges for educators who aspire to foster nurturing learning environments within correctional education structures (Matthews, 2000). For this reason, it is common for some educators who teach in prisons to experience an "adjustment shock" at the beginning of their carceral teaching experiences which could hinder opportunities to establish a rapport with students and effectively address their educational needs (Behan, 2007; Michals \& Kessler, 2015). This shock is typically accompanied by a realization of the major cultural differences existing between inside and outside students, 
classrooms and administrators of education (Matthews, 2000). Indeed, correctional education systems represent a paradox created by the existence of opportunities for educational advancement that are constrained by institutional boundaries designed to repress individuals within, including those who participate in education (Van Gundy et al., 2013).

Educational instruction can be further impaired by spontaneous, and many times unexplained, decisions executed by corrections officers and prison administrators under the auspice of order maintenance. For instance, the already minimal classroom instruction time can be disrupted by corrections officers if they restrict travel to classes for a variety of different reasons including institutional lockdowns and placement in solitary confinement (Osberg \& Fraley 1993). Authority figures may also exercise their power in ways that contravene engagement in postsecondary CE simply because they do not believe in the transformative capability of this educational opportunity (Wright, 1997).

Given such obstacles, there are limited opportunities for mentorship and engagement in higher education available to prisoner students who possess a genuine interest in educational advancement. In this regard, some educators encounter additional struggles related to managing carceral classrooms given threats posed by gang members, student attrition and stringent institutional rules about interactions between prisoners and faculty (Hackman, 2007). These conditions can impact the ease with which faculty are able to culturally adjust to teaching in correctional facilities and also whether they are perceived as trustworthy by incarcerated students (Wright, 2005). As such, encounters between faculty and students are multilayered: managed by prison staff and also reciprocal in nature, largely derived from mutual social learning processes that occur in classroom settings. It is apparent that these relationships are intertwined and shape experiences in postsecondary CE in complex ways.

Pursuing a higher education during incarceration can be simultaneously rewarding and painful given that it is a privilege, the conferral of which is largely subject to the will of others. This paper will enhance existing research by utilizing former prisoners' perspectives to examine the impact of relationships between prisoner college students, other incarcerated individuals, corrections officers and educators on carceral college experiences. It addresses the following research questions: In what ways do carceral strains shape the administration and receipt of postsecondary education in correctional settings? To what extent do interactions between educators, prisoners and corrections officers contribute to a culture of incarceration? How might prisoner college students utilize experiences in postsecondary education to cope with imprisonment pains and other sub-cultural elements of prison?

\section{Data and Methods}

The data were drawn from qualitative interviews with 34 individuals who had completed sentences of anywhere from 3-10 years in various state youth correctional facilities for committing a wide range of both violent and non-violent crimes. This information was collected in 2012, a time when the research participants were between one month and five years post-release. Included within this sample were 30 men, three women and one transgender person. Their ages ranged from 24 to 57, and the average age was 28. In addition, the research participants were racially diverse and self-identified in the following ways: Black (12), Biracial (7), Latino (5), White (5), Asian (3) and Middle Eastern (2). Aside from these differences, they also entered prison with varied levels of educational attainment, which ultimately determined the timing of their eligibility to begin a postsecondary CE. Accordingly, there were 26 interviewees who met the precarceral educational requirements upon entering prison; 11 had some college experience, 12 possessed a high school diploma and three had passed the GED, or General Educational Development, test. The other eight individuals who were part of this study earned GED credentials during their incarceration. Eventually, all 34 research participants met the academic prerequisites for enrollment in carceral college classes.

The study data are based only on postsecondary CE experiences shared by 31 out of these 34 research participants. Although the other three respondents were qualified to take carceral college classes, they did not do so due to a perceived lack of institutional support for involvement in postsecondary CE. One respondent experienced challenges at a systems level in validating his high school diploma and two reported that corrections staff did not encourage and/or support prisoner participation in college. For these reasons, three research participants did not pursue college during incarceration, but did so afterwards. 
At the time of this study, all research participants were former or current students at a four-year state university, referred to by the name "State University" in this essay. Their admission to this institution was facilitated through membership in a higher education program for previously incarcerated individuals. To be eligible for this program, here named "Project Achieve," applicants had to possess a GED or high school diploma, earn at least 12 hours of transferable college coursework, maintain close to a 3.0 grade point average and not incur any major disciplinary infractions during incarceration.

Using these criteria, there were 53 potential participants consisting of past and present students enrolled in State University vis-à-vis their membership in Project Achieve. The program director provided email addresses and cell phone numbers, excluding contact information for two persons who withdrew from the program and remained out of touch. I first made phone contact with each of them and then sent a follow up email communication. This provided an initial overview of the study, outlining its purpose, the benefits and risks associated with participation, informed consent and anonymity. Actual interview responses were made anonymous through the use of pseudonyms assigned to each respondent.

Aside from the two aforementioned withdrawals, there were 17 potential participants who were not included in the study sample for other reasons, which are discussed below. I had contact information for five of these individuals, but did not reach out to them because they were either finishing their sentences at a halfway house or re-incarcerated in federal prison at the time. An administrator at the halfway house where three potential participants were staying explained that resident participation in my study was not permitted. Two persons who were in federal custody were excluded in order to avoid any possible threats to confidentiality posed by institutional infringements on communications with prisoners. Eight individuals did not respond to calls and emails, another three did not appear at their scheduled interviews, and one remained unreceptive to my attempts to reschedule a cancelled interview. The remaining 34 persons responded either by phone or email and each took part in a subsequent qualitative interview, described in more detail below.

The interviews were conducted in a quiet, convenient location on or near State University to minimize any additional travel costs for participants. Interviewees received a nominal fee of $\$ 25$, paid for through a small research grant in exchange for their participation. This involved responding to open-ended questions about their experiences in education and crime before, during and after incarceration. The data were transcribed and sorted into these main categories and then further organized into related subgroups. For purposes of this paper, research participants were asked to recount their experiences taking carceral college classes including any general challenges stemming from institutional contexts. They were not asked to describe specific problems arising from interactions with other prisoners, corrections officers or faculty. $\quad \mathrm{R}$ a $\mathrm{t} \mathrm{h}$ e $\mathrm{r}$, these themes emerged organically as part of an inductive analytical process, a technique that can buffer the potential for telescoping or faulty memory recall in retrospective interview responses (Carbone \& Miller, 2012). Responses relevant to involvement in postsecondary education in prison were categorized into subgroups based on interactions with other prisoners, faculty and corrections officers. Logical inferences were drawn regarding the connections between carceral encounters and college experiences in prison. The research findings closely align with well-documented research on pains associated with imprisonment (Sykes, 1985; See also Cochran, et al., 2014; Listwan et al., 2013; Morris et al., 2003).

The findings have limited generalizability; however, since they are based on experiences shared by former incarcerated college students, they can potentially enhance understanding about the benefits and drawbacks of participation in postsecondary education in correctional settings.

\section{Carceral Relationships and Postsecondary Correctional Experiences}

Participants in this qualitative study included 34 formerly incarcerated individuals who were past and present students in a higher education program, however only 31 had been involved in postsecondary CE. Differences in sentence length and correctional facility rules attributed to limitations on eligibility, class availability and progress toward course completion in varied ways. Nonetheless, 31 out of the 34 respondents began or in some cases resumed taking college classes during their former incarceration and in that respect shared in common recollections about the benefits and drawbacks of taking postsecondary courses in prison. An inductive analysis of their responses to open-ended questions revealed important themes about carceral relationships and postsecondary experiences in correctional settings. The data were used to draw inferences 
about how a culture of incarceration influenced such interactions between incarcerated college students, their keepers, others who are kept behind bars and educators. This research also revealed specific ways that these socio-cultural prison characteristics impact involvement in postsecondary CE.

The results of this study show that encounters in postsecondary education in prison are complex, connected and often times difficult to manage. These formerly incarcerated individuals who took college courses in prison recalled feeling both frustrated by such circumstances and appreciative of the opportunity to take college classes during such a vulnerable time. Involvement in postsecondary CE was described as a temporary, figurative (mental) escape from confinement. The experience gave rise to thoughts about how continued participation in higher education might help to secure a better future post-release. Some participants entered prison with exceptional levels of pre-carceral educational attainment and for that reason were better positioned to perceive higher education as an avenue for change, enroll in college classes and focus on course content despite contextual challenges related to incarceration. Regardless, study participants described burdens and rewards associated with being a prisoner college student as integral to the experience of imprisonment and carceral interactions with other incarcerated persons, correctional staff and educators.

\section{Experiencing Postsecondary Education in Correctional Settings}

Institutional confinement is a form of coerced isolation that contributes to imprisonment pains. It takes physical, emotional, psychological and social forms. Yet, such encompassing separation and discomfort is also characterized by conditions that are conducive for engagement in postsecondary CE, given the absence of typical challenges faced by college students on the outside. All of the respondents who had previous carceral experience in higher education described their controlled movements for work and other activities as part of a daily routine. This imposed structure was, at least in theory, conducive to academic time management. For instance, Javeen referred to some struggles he faced while attending college post-release to explain that engaging in postsecondary $\mathrm{CE}$ was easier because:

You don't have distractions like you don't have full time job, you don't have work. You have a job assignment when you're in there but everything is scheduled. You manage your time according to timeslots.... When you're home you have to pay bills, you have to work, you have a bunch of other things going on so. I feel like you have to have a certain level of determination, drive, focus. If you have that then it's easy to do.

As Javeen highlighted, involvement in structured movements during incarceration brought along an increased potential for engagement in postsecondary CE. It also diminished the prospect of external obstacles and concerns interfering with educational pursuits. To that end, Mike explained that incarcerated students have "all the time in the world" and from his experiences the college courses offered "weren't too challenging." Similarly, Ulysses stated that "it's easy to be in there [prison]" because "you not around your friends, there's no parties, there's no liquors, no drugs, there's no females." It is evident that incarcerated individuals are confined to artificial settings and cut off from mainstream society; these circumstances can be ripe for higher learning. As Oliver put it, "you know in that environment anything is appealing and interesting." However, the question remains as to whether the participants were truly presented with the situational opportunities and actual support needed to engage in critical aspects of higher learning such as classroom lectures and discussions. The next section will focus on carceral classroom settings, the dynamics between students and the impact on levels of engagement in course material and instruction.

\section{Classroom Interactions Between Incarcerated College Students}

Those participants who completed some postsecondary CE had served time at different state correctional facilities, yet they shared similar accounts about interactions that occurred in prison classrooms and how these features influenced academic experiences. To start, college enrollment was open to all eligible persons, which posed challenges for both prisoner students and faculty. In the correctional education system, eligibility for college classes is based on GED attainment or receipt of a high school diploma. Unlike in the outside world, there are no standardized test scores, personal statement submissions or other measures used to determine individual skill level, ability and desire to pursue a higher education. Oliver spoke directly about the implications of such comparatively lax enrollment requirements on carceral classroom dynamics. He stated “it's a little different 'cause some people are serious and some aren't. So you have the people that are jokers 
you know and they're just there to be there, just to get out a little while...other people, you know take it more seriously and have respect for the teachers that come in. So there's some mix." Likewise, Yvette described the carceral classroom atmosphere as one geared more towards "playing around" because not all students seemed to take education seriously.

Victor gave specific examples of why some prisoners might choose to take college courses for reasons unrelated to a genuine interest in receiving a higher education:

Some people did it because they was bored. Other people did because they seen the bigger picture like this is my way out...this is my way away from the streets. Other guys seen it as an escape 'oh I'm gonna do college so I don't have to do these programs.' Or 'I'm gonna take college so I don't have to be in the cottage all day' or 'I'm gonna do college so I don't have to be in the CO's face...I'm getting some kind of movement.' It was like some people, the intention was not good. A lot of times you have rival gangs all in the same [classroom] so you don't know what could happen right there.

Overall, the study participants identified lack of genuine commitment to higher education and threats of gang conflict presented by some classmates as two factors that shattered idealistic views of prisons as conducive learning environments. For instance, Ever, who described the beginning of every semester as a "free for all," further explained that "nearly everybody's affiliated or associated with a gang or whatever the case may be." He recalled how these individuals served as a reminder that "you have distraction[s] all around you...you're still an inmate, you're still in prison, you still have to look over your shoulder and watch what's going on around you."

Victor too remembered that "you could just feel the tension" and even though "nothing physical ever happened," there were "subliminal [messages] thrown out" during class "and that was a little uneasy, nerve racking." He responded to this situation by keeping his distance from any students whom he believed were gang affiliated or otherwise in class to cause disruptions. Ever did the same but explained that he had to make a concerted effort to avoid negative influences and pay attention in class. As he put it, "it was your choice to engage yourself in the class and participate and everything. I sat in front, asked questions constantly, had my hand raised, always listened...tried to follow." Similarly, Ethan acknowledged that being an incarcerated college student was stressful, but he coped with that situation by remaining "in the front of the classroom, eyes on the professor, chalkboard or whatever was going on." He went on to say, “anything behind me, I didn’t pay attention to [it] unless it was classroom discussion."

Coincidentally, it was during class discussions accompanied by lectures and presentations that unengaged students were likely to disrupt the focus of others who were truly interested in advancing their education. The study results also showed that prison sub-cultural influences often contributed to such behaviors. As an example, Henry explained that incarcerated students often engaged in "jailing" or exchanging verbal statements during class, in jest and for the purpose of interfering with learning processes. During his time served, he observed "jailing" occur daily and explained the potential impact on others, especially pupil bystanders like himself:

Could you imagine being in a room with a bunch of class clowns?.... There's a lot of joking, a lot of class disruptions. A lot of guys in prison joke a lot they call it jailing...joking to pass the time. So a lot of times they would single somebody out and just jail on them and just make fun of them....If you're the butt of that session, don't get mad because that's how fights happen. So jailing would happen in class they would jail off the teacher and she doesn't know it's jailing... they're playing dumb when they really know the answer. You know it's so many different ways to do it.

Henry revealed that his perception about the quality of postsecondary CE began to change upon the realization that not every college enrolled prisoner was motivated to learn. As he stated, "I took it seriously, but I didn't take it as seriously as I did the first couple of days when I'm like 'I'm ready to learn, and oh here we go you're gonna "jail" the whole time."” Much like Henry, Marcos expected more than he received from 
his carceral college education. More specifically, he thought these college classes would be administered through a "more structured, well organized...rigorous program." Instead, Marcos discovered that "in prison it's lax, people joking." He used his public speaking class as an example and mentioned that "there was only four people that actually took their speeches seriously...that really tried to do well on their speeches." Marcos expressed disappointment over the lackadaisical attitudes displayed by some of those classmates.

Albert too described jailing and academic indifference as pervasive aspects of a broader prison subculture, which strongly influenced his approach to opportunities for higher learning during incarceration. A self-proclaimed introvert, he was at first hesitant to actively participate in class activities given the likelihood that other students would make playful or hurtful comments if he were to make any mistakes. As he put it, "I'm not really a people [person]....and those classes especially in there, in prison...it's like you're amongst comedians. If you say the wrong thing, if you look a certain way...you know." Regardless, Albert turned such negativity into motivation for stellar academic performance as follows: "In a way, it just made me want to... know whatever I was saying or what I was writing. It encouraged me to do better and try to perfect it in a way."

Other respondents, including Henry and Marcos, also found ways to navigate through classroom distractions and earn good grades. Indeed there were other relevant factors besides classroom disruptions that contributed to participants' experiences in postsecondary CE. ${ }^{3}$ Generally speaking, Javeen believed that incarcerated persons who tried to engage in college classes possessed a genuine desire to change and "a more serious outlook on life" compared to others who did not. As he further suggested, "that also played a difference in the mentality of the classroom...how people acted towards each other, towards the professor."

\section{Encounters Between Incarcerated College Students and Prison Educators}

Overall, the research participants were motivated to successfully complete the college courses they enrolled in during incarceration, regardless of any challenges posed by other prisoners. Yet, all 31 individuals who were enrolled in college classes at that time identified interactions with professors as another salient factor in shaping levels of educational engagement, focus on classroom instruction and perceived quality of postsecondary CE received. Furthermore, these prisoner college student-faculty relationships developed in correctional institutions, where rapport was shaped by many contradictory forces. This section will cover participants' accounts about the reciprocal nature of their interactions with educators along with how these encounters varied, influencing carceral college experiences in different ways. Indeed, as Oliver expressed, from an academic standpoint, faculty who come to teach in prisons are "not working with anything great so to speak," yet "some are more motivated to teach and to help the students learn, and others probably they just do the minimum."

Research participants gauged faculty members' level of interest and sense of comfort teaching in carceral settings based on classroom interactions they had with them. Shared conversations and actions, both implicit and overt, were described as intrinsically related and influential in shaping perceptions about the quality and value of postsecondary CE received. More specifically, these formerly incarcerated individuals reported having more favorable college experiences in prison when enrolled in courses taught by professors who did not make them feel inferior or otherwise stigmatized. To that end, Yvette remembered one educator in particular who demonstrated such professional attributes and for that reason quickly gained the trust and admiration of her students:

In the classroom, with that teacher...it was no different than being in society. She didn't judge us 'cause we were incarcerated. Her job was to teach and she did it and the kids were overwhelmed by it. Everybody would want to stay the next period and they would cancel gym...'cause they used to want to learn....It was a good learning environment.

Wayne expressed the same sentiment, adding that "those [postsecondary CE] experiences where we were pushed, you know people didn't see us as a project or students that needed to be pampered or babied" increased his confidence about pursuing a college education during incarceration.

On the other hand, taking carceral college classes taught by instructors who were seen as less focused 
on stimulating academic advancement could have the opposite effect on postsecondary CE experiences. Ivan expressed disappointment over the caliber of higher education that he received on the inside. As he stated, "I definitely would want to see the professors push us a little more....I felt [that]...the professor is gonna pass most people just for showing up, doing the basic stuff." Dexter shared the same perspective, as he stated: "I don't think they actually graded upon your academic performance." Furthermore, Fred, who recalled some similar past experiences, suggested that any perceived indifference on the part of prison educators reflected the fact that those individuals "didn't really care" and were "just there getting a paycheck, an extra paycheck." As a result, these and other research participants felt less motivated to pay attention in class, complete course assignments and study for exams when professors implemented minimal to no structured curriculum standards.

An important facet of student-educator interactions were faculty approaches to teaching that were expressed through verbal exchanges, and together influenced whether prisoners felt more or less like traditional students and inspired to learn. Accordingly, Kerri characterized her relationship with a former professor during incarceration as "personal...like you had somebody who had taken the time out of their own schedule to come and do this...it made you want to try harder." She felt this way mostly because he once told her: "I think everybody should go to jail before they come to college because you guys are the most dedicated people I've ever met in my entire life." For Kerri, this encouraging statement, which was reinforced by action, motivated her to excel academically.

Jaeger also commented on the reciprocal nature of relationships between incarcerated students and faculty, noting that "the class goes according to the instructor." He remembered one teacher in particular whom students generally regarded as "just mad cool" because "he would talk about the paper, he would read with you, he would let you know what was going on outside, tell you the news or whatever...it was just that vibe off." Jaeger suggested that this time spent building a rapport with students came at a price because the "work load, it was light." Yet because students respected this teacher, classroom disruptions remained at a minimum. As Jaeger put it, "we would still bullshit but, we wouldn't do it in front of his face." Randy more readily seized opportunities to learn from prison educators who were seemingly dedicated to supporting academic growth among incarcerated students. He shared the following experience as a student in a course that he called 102: "The teachers, they talked, they shared a lot of things with me. Books, they would bring in for me and everything and...I had fun. I was having fun doing those assignments and...the grades show. I had a $\mathrm{C}$ in 101 and then I had a A in 102."

Fred also credited his strong academic performance in certain classes to faculty members who seemed committed to developing carceral environments that were conducive to learning. However, he explained that reaching the level of mutual trust between incarcerated students and faculty needed to help facilitate higher learning in prison was a gradual process and one constrained by carceral norms and limitations. Specifically, Fred mentioned that in his experience most prison educators are "kinda standoffish, especially at the beginning" and those that do get warmed up, "by that time...the class is over." Much like him, Albert characterized his involvement in postsecondary $\mathrm{CE}$ as a valuable experience, yet one that had could have been more gratifying. As he put it, "I learned some things, but I didn't learn everything that I could because the teachers...they were pressured in a way 'cause they wanna do something good for people, and in a way sometimes...they felt vulnerable." 4

The results of this study revealed that individuals who visit prisons to teach might require some time to adjust to this temporary confinement, particularly given their susceptibility to student conflicts and discretionary decisions executed by corrections officers and facility administrators. This predicament is ironic because the time typically needed to effectively teach and forge relationships with incarcerated students is not guaranteed, but instead made inconsistent due to restricted access to enrolled classes. For example, Xander described in detail how corrections officers might use their power in ways that circumvent access to prison education and uninterrupted academic instruction. He used the following analogy to illustrate this point:

It's kinda like their [educators'] hands are tied, our hands are tied and you have the overseers. So it's like you have the watchdog, you have the inmate and you have the people coming to offer the services. So we basically gotta travel by whatever rules they have, or whatever ways they're feeling..." 
As a result, he revealed that corrections officers might arbitrarily prevent prisoners from attending classes but most professors are aware of this condition and try to accommodate students who are absent. Given the well-established link between participation in postsecondary CE and post-release success, this inquiry into the role of corrections officers in shaping these educational experiences is much needed. The next section will focus on corrections officers and how they might utilize their discretion in ways that impede carceral movements and in turn, opportunities and motivation to successfully complete college classes.

\section{Relationships Between Prisoner College Students and Corrections Officers}

The 31 research participants who earned college credits during their former incarceration had varied interactions with corrections officers that were linked to their participation in postsecondary CE. Major components of these encounters were verbal opinions expressed by $\mathrm{COs}^{5}$ about the value of respondents' involvement in higher education and the ways in which these statements impacted the respondents' carceral educational experiences. The respondents recalled instances where corrections officers expressed these thoughts through actions that obstructed the respondents' freedom to attend college classes. Adding to this problem was the fact that corrections officers often did not explain their reasons for imposing such limitations, which fueled assumptions that the intended purpose was to exert control by thwarting educational progress.

Notably, research participants did not portray every encounter with corrections officers in a negative light. Yet, they expressed that it was atypical for COs to overtly support participation in postsecondary CE. Ivan illustrated this point in the following account:

Generally, their attitude[s] [are] pretty cynical of...anything the inmates are trying to do to benefit themselves whether its religion, education. Not every officer, but in general there seems to be an attitude of cynicism like.... I mean the officers are worse than the inmates sometimes. Just their attitudes in general about life and their attitudes toward women and education and all that stuff.....It was more of like a negative vibe about it.

Similarly, Farley acknowledged that "there were some [corrections officers] that just supported us not coming back" but concluded that most "were just ignorant....they just didn't really care about you." Much like Ivan, he noted the power of institutional norms and behaviors, explaining that "the way our culture is structured, incarceration...it's not really geared toward rehabilitation....It's more geared toward just the housing prospect."

A common theme that emerged from the study results was that research participants viewed COs as being more concerned with institutionalizing prisoners rather than understanding how to support their involvement in higher education and the development of alternative pathways to crime. The data revealed that an important facet of this problem was restrictions on carceral movements, which interrupted access to classrooms and were largely perceived as arbitrarily imposed. For instance, Nate recalled that "even though there are only certain lock in times, the officers on the unit would be like 'I don't feel like watching you. Go in your cell." He described this as a fairly common control tactic used by corrections officers and surmised that it was allowed because they are authorized to "call a random count any time they think the numbers might be off."

Regardless of the actual reasons behind unexpected cell confinement, the result was that incarcerated students were locked in their cells during times that could have been spent inside the classroom. Marcos recounted his experience in trying to navigate custodial control over access to carceral college classes:

A lot of times I missed class because of the officers and the prison itself...sometimes they announce it [the authorization for travel to classes] later or they don't announce it....If the announcement doesn't go through, then the officer is not gonna open the door even though the officer sees people going to college.

Isaiah spoke about how these practices might also create tension between students, teachers and corrections officers, as he revealed that "when you go to school...that's an inconvenience. The cops may not wanna let you out...but I liked going to school." Furthermore, Isaiah revealed that "there was always a conflict between the education department and custody," because, for example, "if a fight may have happened earlier that day, they may try their best not to let school out.... So any little thing that happens, they try to just get rid 
of school." Although Albert served time in a different correctional facility, he remembered facing similar administrative roadblocks because "they [prisoner administrators] were constantly pushing to eliminate schooling and programs and vocational shops" in order to relieve corrections officers from the burdens of managing travel back and forth to classrooms.

Overall, research participants perceived corrections officers as misusing their discretionary powers for the purpose of blocking efforts to participate and engage in postsecondary carceral education. However, Isaiah further suggested that their motives were more "cynical, like they don't want you to learn something.... They want you to go back out there and commit a crime and come back." As such, Ethan believed corrections officers "basically want you to stay stagnated in your mindset that jail is the thing to do" in order to more readily assimilate incarcerated persons into prison cultures. He further explained that requiring prisoners to complete daily structured routines leaves very little, if any, time for participation in postsecondary CE. Ethan illustrated this point with the following example: "correctional officers would always tell us certain things we had to do as far as lock in, what time we gotta eat, what time we gotta be up for group....They made us tuck in our shirts, but they would never tell us to go to school."

It is apparent that corrections officers said little, if anything to motivate respondents' progress toward college completion, but they made up for this silence by making rude and disparaging comments about postsecondary CE to both prison educators and prisoner students. Research participants discussed how such statements exacerbated already strained prison environments. For instance, Victor asserted that COs "can't stand education" based on comments he overheard some of them make in regards to prison based higher education. He remembered that "they would tell the teachers, 'I don't even know why you're here. I don't know why you're working...this is not gonna get through these guys heads, you're wasting your time.....These guys are too dumb."”

Furthermore, other respondents shared recollections about statements corrections officers made directly to them, about their own involvement in higher education. To start, Ever revealed that "they're always trying to berate you for it [taking college classes]" and recalled a few telling him 'oh, now you're trying to go to school, just because you got locked up...you have nothing else to do.' As Fred put it, "some of them...they don't get mad, but they try to make fun of you" by "saying little slick comments like 'oh, you wasn't doing that [going to college] on the streets."”

The research participants found it impossible to avoid such negativity as they regularly encountered corrections officers during scheduled movements throughout each day. They spoke about how these circumstances impacted their focus on academics and motivation to succeed in higher education. Ivan summed up this point, explaining that "how officers generally interact with inmates, it just carries over to whatever you're doing and particularly when it comes to...trying to better yourself, which education is..." It is quite possible that some incarcerated students might become disengaged from higher education in response to belittling remarks and contravening actions, but the study results revealed just the opposite. For instance, Geoff noted some possible implications of unfavorable interactions between prisoners and corrections officers:

How they treat you in there.... What you think the outcome is gonna be of that? It's gonna be a small proportion that's gonna be like nah I gotta elevate from this, I gotta stop coming back here. But, the majority like...'I'm a con, I'll be the best con I can be then'...because you're not teaching them nothing besides that.

The other formerly incarcerated persons who gained some college experience during incarceration identified engagement in postsecondary $\mathrm{CE}$ as one way to avoid this self-fulfilling prophecy. As Ivan expressed, "I think really with a lot of guys, [they] appreciate the opportunity...being able to go to class and... just getting your mind off the bullcrap and being able to focus on something that's beneficial like education." Similarly, Fred explained that strained encounters he had with corrections officers just made him "want to do it [take college classes] more, improve more." From this standpoint, the mere chance for change, presented through enrollment in carceral college classes, gave research participants a sense of hope and motivation to persevere beyond imprisonment pains.

The data revealed that involvement in postsecondary $\mathrm{CE}$ can provide opportunities for prisoners to 
cope with the strains of incarceration in useful ways; however, certain social interactions and cultural factors were described as inherent to imprisonment and also counterproductive to advanced educational pursuits. There were 31 out of 34 research participants who earned carceral college credit(s). Their engagement in higher education depended upon interactions with other students, prison educators and corrections officers, all of whom influenced access to carceral classrooms and corresponding opportunities for academic learning. Nonetheless, respondents voluntarily took and completed college classes during their incarceration, an indication that they remained focused, at least to some extent, on higher education regardless of any distractions presented in or out of the classroom.

The study results broaden understanding of the distinct yet overlapping institutional challenges that typically accompany participation in postsecondary CE. More importantly, this research draws specific and much needed attention to some of the pains of imprisonment and outlines some of the ways in which these circumstances can be mitigated through involvement in postsecondary CE. The data demonstrates the power of higher education received during incarceration and can be used to bolster support for the current and future development of postsecondary CE programs.

\section{Discussion}

The focus of this paper was on the experiences in postsecondary CE of 31 formerly incarcerated individuals who also continued their involvement in higher education post-release. The main purpose was to explore specific ways in which imprisonment pains influenced postsecondary educational experiences in correctional settings. Central to this inquiry was understanding how such strains impacted encounters that research participants had with other students, non-students, prison educators and corrections officers during incarceration. These interactions were largely governed by institutional structures predicated upon a system of restrictive rules and procedures. Respondents characterized such circumstances as part of a culture of incarceration that both constrained and facilitated higher learning in prison.

When research participants first entered prison, they assumed that participation in postsecondary classes would be unencumbered given the disconnect from life challenges or disruptions typically faced outside of prison. Yet, after beginning a postsecondary CE, it became clear that this ideal did not accurately depict the reality of being an incarcerated college student. In prison, respondents were socially isolated and as a result their interactions with professors, corrections officers and other prisoners were important elements of their experiences in postsecondary education. These relationships emerged in controlled environments, factors that had a dichotomous impact on carceral college participation.

For example, some respondents recounted how some corrections officers made disparaging remarks about their college participation and restricted their physical movements in ways that threatened to or did contravene their efforts to attend classes. The latter further diminished the already limited time allotted for prison education. Taken together, such structural impediments also made it difficult for prison educators to build relationships with students and effectively administer academic instruction to absentees confined to their cells or administrative segregation. The data showed that this situation was further complicated by incarcerated students who were characterized as being uninterested in learning and instead focused on mocking others during class or otherwise using that time to socialize. In sum, the research participants had continuous interactions with other prisoners, prison educators and corrections officers who influenced their college experiences in both positive and negative ways.

Interestingly, all research participants remained engaged in postsecondary CE despite some challenges presented by other prisoners, professors and corrections officers. They described such hardships as inherent features of incarceration that made them feel frustrated, yet at the same time inspired them to use their involvement in postsecondary $\mathrm{CE}$ as an avenue for change and progress. As such, the respondents described their participation in college during incarceration as an escape from associated pains of imprisonment, albeit temporarily. However, their ambition and willingness to perceive that educational experience as valuable could be attributed to a selection bias. Eleven out of the total 31 research participants who took college classes in prison also attended college prior to incarceration. Regardless, this qualitative study gathers the perspectives of formerly incarcerated individuals to offer unique insights into the benefits and challenges of carceral 
college participation including specific ways that such efforts are based on interactions with others in prison contexts.

Although these study results are grounded in theoretical frameworks, they cannot be generalized to all incarcerated college students due to the situated nature of qualitative research design. Nonetheless, the data will strengthen relevant research on postsecondary $\mathrm{CE}$, which mostly centers around practitioner experiences, prison classrooms, pedagogy, and characteristics of incarcerated students (Matthews, 2000; Michals \& Kessler, 2015; Montross \& Montross, 1997; Wright, 2005). By comparison, this qualitative research is based on the narratives of individuals who were once incarcerated college students and in that regard can contribute to a more unique portrayal of the interrelationship between specific carceral features that influence prisoner involvement and success in postsecondary CE. The policy implications are far reaching since bringing attention to challenges that accompany participation in postsecondary $\mathrm{CE}$ can help improve college administration and higher learning experiences in prisons.

\section{Notes}

1. This term is used interchangeably with postsecondary CE to refer to higher education programs offered in prison for transferable college credit(s).

2. Congress banned prisoners from receiving Pell Grants with the passage of The Violent Crime Control Act of 1994. In 2015, the U.S. Education Department and Justice Department announced a new pilot program designed to reinstate Pell Grant availability for federal prisoners who pursue a higher education during incarceration.

3. Marcos and Henry were among 11 out of 34 respondents who entered prison with some college experience; an exceptional level of pre-carceral educational attainment compared to most state prisoners. Henry directly acknowledged this learning gap stating, "I was educated in the Catholic School system and I had been to college before a lot of guys. These [carceral courses] were their first [college] classes taken... I'm not the average person that goes to prison....I actually had opportunities, I had resources, I had both my parents..."

4. Albert further explained that prison faculty might feel vulnerable because they are "in a room...with 30 guys...you don't know what they're here for so...they might be a little afraid....Then you have guys that are just straight, you know gangbangers and...so they just they would go in there [classrooms] for meetings or whatever their case may be."

5. Research participants used the words "COs", "cops" and "police" as colloquial terms for corrections officers.

\section{References}

Agnew, R. (2001). Building on the foundation of general strain theory: Specifying the types of strain most likely to lead to crime and delinquency. Journal of research in crime and delinquency, 38(4), 319-361. https://doi.org/10.1177/0022427801038004001

Agnew, R. (2006). Pressured into crime: An overview of general strain theory. Oxford University Press, USA.

Anders, A. D., \& Noblit, G. W. (2011). Understanding effective higher education programs in prisons: Considerations from the incarcerated individuals program in North Carolina. Journal of Correctional Education, 77-93.

Batiuk, M. E., Lahm, K. F., McKeever, M., Wilcox, N., \& Wilcox, P. (2005). Disentangling the effects of correctional education Are current policies misguided? An event history analysis. Criminal Justice, 5(1), 55-74. https://doi.org/10.1177/1466802505050979

Behan, C. (2007). Context, creativity and critical reflection: Education in correctional institutions. Journal of Correctional Education, 157-169.

Blevins, K. R., Listwan, S. J., Cullen, F. T., \& Jonson, C. L. (2010). A general strain theory of prison violence and misconduct: An integrated model of inmate behavior. Journal of Contemporary Criminal Justice, 26(2), 148-166. https://doi.org/10.1177/1043986209359369 
Carbone-Lopez, K., \& Miller, J. (2012). Precocious Role Entry as a Mediating Factor in Women's Methamphetamine Use: Implications for Life-Course and Pathways Research. Criminology, 50(1), 187-220. https://doi.org/10.1111/j.1745-9125.2011.00248.x

Chappell, C. A. (2004). Post-secondary correctional education and recidivism: A meta-analysis of research conducted 1990-1999. Journal of Correctional Education, 148-169.

Cochran, J. C., Mears, D. P., \& Bales, W. D. (2014). Assessing the effectiveness of correctional sanctions. Journal of Quantitative Criminology,30(2), 317-347. https://doi.org/10.1007/s10940-013-9205-2

Crewe, B. (2011). Soft power in prison: Implications for staff-prisoner relationships, liberty and legitimacy. European Journal of Criminology, 8(6), 455-468. https://doi.org/10.1177/1477370811413805

Dye, M. H. (2010). Deprivation, importation, and prison suicide: Combined effects of institutional conditions and inmate composition. Journal of Criminal Justice, 38(4), 796-806. https://doi.org/10.1016/j. jcrimjus.2010.05.007

Gordon, J. A., Proulx, B., \& Grant, P. H. (2013). Trepidation among the "keepers": Gendered perceptions of fear and risk of victimization among corrections officers. American Journal of Criminal Justice, 38(2), 245-265. https://doi.org/10.1007/s12103-012-9167-1

Hackman, K. M. (1997). Correctional education - Challenges and changes. Journal of Correctional Education, 48(2), 74-77.

Johnson, R. (2001). Hard time: Understanding and reforming the prison. Belmont, CA: Wadsworth.

Kaposy, C., \& Bandrauk, N. (2012). Prioritizing vaccine access for vulnerable but stigmatized groups. Public Health Ethics, phs010. https://doi.org/10.1093/phe/phs010

Kim, R. H., \& Clark, D. (2013). The effect of prison-based college education programs on recidivism: Propensity Score Matching approach. Journal of Criminal Justice, 41(3), 196-204. https://doi. org/10.1016/j.jcrimjus.2013.03.001

Kuhlmann, R., \& Ruddell, R. (2005). Elderly jail inmates: Problems, prevalence and public health. Californian Journal of Health Promotion, 3(2), 49-60.

Listwan, S. J., Colvin, M., Hanley, D., \& Flannery, D. (2010). Victimization, Social Support, and Psychological Well-Being A Study of Recently Released Prisoners. Criminal justice and behavior, 37(10), 1140-1159. https://doi.org/10.1177/0093854810376338

Listwan, S. J., Sullivan, C. J., Agnew, R., Cullen, F. T., \& Colvin, M. (2013). The pains of imprisonment revisited: The impact of strain on inmate recidivism. Justice Quarterly, 30(1), 144-168. https:// doi.org/10.1080/07418825.2011.597772

Matthews, S. (2000). Each day is a challenge: Paving the way for success in the prison classroom. Journal of Correctional Education, 179-182.

Meyer, S. J., \& Randel, B. (2013). The Impact of an Associate's Degree Program for Incarcerated Students A Randomized Trial of the Correctional Education Association College of the Air Program. Community College Review, 41(3), 223-248. https://doi.org/10.1177/0091552113497787

Michals, I., \& Kessler, S. (2015). Prison Teachers and Their Students: A Circle of Satisfaction and Gain. Journal of Correctional Education, 66(3), 47.

Montross, K. J., \& Montross, J. F. (1997). Characteristics of adult incarcerated students: Effects on instruction. Journal of Correctional Education, 179-186.

Morris, R. G., Carriaga, M. L., Diamond, B., Piquero, N. L., \& Piquero, A. R. (2012). Does prison strain lead to prison misbehavior? An application of general strain theory to inmate misconduct. Journal of Criminal Justice,40(3), 194-201. https://doi.org/10.1016/j.jcrimjus.2011.12.001

Osberg, T. M., \& Fraley, S. E. (1993). Faculty perceptions of teaching in a prison college program: motivations, barriers, suggestions for improvement, and perceived equivalence to traditional college programs. Journal of Correctional Education, 20-26.

Palmer, S. M. (2012). Postsecondary CE Recognizing and Overcoming Barriers to Success. Adult Learning, 23(4), 163-169. https://doi.org/10.1177/1045159512457918

Sykes, G. M. (2007). The society of captives: A study of a maximum security prison. Princeton University Press.

Toch, H., Adams, K., \& Greene, R. (1987). Ethnicity, disruptiveness, and emotional disorder 
among prison inmates. Criminal Justice and Behavior,14(1), 93-109. https://doi. org/10.1177/0093854887014001008

Van Gundy, A., Bryant, A., \& Starks, B. C. (2013). Pushing the envelope for evolution and social change: Critical challenges for teaching inside-out. The Prison Journal, 0032885512472691. https:// doi.org/10.1177/0032885512472691

Whiteside, L. (2015). Obama to offer Pell grants to prisoners. CNN Money. Retrieved from http://money.cnn. com/2015/07/29/news/inmates-pell-grants-obama/.

Winterfield, L., Coggeshall, M., Burke-Storer, M., Correa, V., \& Tidd, S. (2009). The Effects of Postsecondary CE:" Final Report". Urban Institute (NJ1).

Wright, R. L. (1997). Towards integrative correctional education programs: Some obstacles, some suggestions. Journal of Correctional Education, 10-22.

Wright, R. (2005). Going to teach in prisons: Culture shock. Journal of Correctional Education, 19-38.

Lindsey Livingston Runell JD, PhD, is an assistant professor of criminal justice at Kutztown University. Her research experience covers issues related to incarceration, higher education and desistance from crime. Her future research includes an upcoming longitudinal study that examines psychosocial correlates of bullying among middle school student cohorts. 